Gut and Liver, Vol. 11, No. 5, September 2017, pp. 642-647

\title{
Comparison of the Outcomes of Peroral Endoscopic Myotomy for Achalasia According to Manometric Subtype
}

Won Hee Kim ${ }^{1}$, Joo Young $\mathrm{Cho}^{1}$, Weon Jin Ko${ }^{1}$, Sung Pyo Hong ${ }^{1}$, Ki Baik Hahm ${ }^{1}$, Jun-Hyung $\mathrm{Cho}^{2}$, Tae Hee Lee ${ }^{2}$, and $\mathrm{Su}$ Jin Hong ${ }^{3}$

${ }^{1}$ Digestive Disease Center, CHA Bundang Medical Center, CHA University, Seongnam, ${ }^{2}$ Digestive Disease Center, Soonchunhyang University Hospital, Seoul, and ${ }^{3}$ Digestive Disease Center, Soonchunhyang University Bucheon Hospital, Bucheon, Korea

Background/Aims: We evaluated whether manometric subtype is associated with treatment outcome in patients with achalasia treated by peroral endoscopic myotomy (POEM). Methods: High-resolution manometry data and Eckardt scores were collected from 83 cases at two tertiary referral centers where POEM is performed. Manometric tracings were classified according to the three Chicago subtypes. Results: Among the 83 cases, 48 type I, 24 type II, and 11 type III achalasia cases were identified. No difference was found in pre-POEM Eckardt score, basal lower esophageal sphincter (LES) pressure, or integrated relaxation pressure (IRP) among the type I, type II, and type III groups. All three patient groups showed a significant improvement in postPOEM Eckardt score (6.1 \pm 2.1 to $1.5 \pm 1.5, p=0.001 ; 6.8 \pm 2.2$ to $1.2 \pm 0.9, p=0.001 ; 6.6 \pm 2.0$ to $1.6 \pm 1.4, p=0.011$ ), LES pressure $(26.1 \pm 13.8$ to $15.4 \pm 6.8, p=0.018 ; 32.3 \pm 19.0$ to $19.2 \pm 10.4, p=0.003 ; 36.8 \pm 19.2$ to $17.5 \pm 9.7, p=0.041$ ), and 4 s IRP $(21.5 \pm 11.7$ to $12.0 \pm 8.7, p=0.007 ; 24.5 \pm 14.8$ to $12.0 \pm 7.6, p=0.002 ; 24.0 \pm 15.7$ to $11.8 \pm 7.1, p=0.019$ ) at a median follow-up of 16 months. Conclusions: POEM resulted in a good clinical outcome for all manometric subtypes. (Gut Liver 2017;11:642-647)

Key Words: Esophageal achalasia; Peroral endoscopic myotomy; High resolution manometry; Treatment outcome

\section{INTRODUCTION}

Achalasia is an esophageal motility disorder of unknown cause. Achalasia is characterized by impaired relaxation of the lower esophageal sphincter (LES) and absent esophageal peristalsis, due to neuronal degeneration of the myenteric plexus. Estimated incidence is 1 per 100,000 per-year with a peak inci- dence between the ages of 30 and 60 years. ${ }^{1}$

Available treatment options for achalasia are oral pharmacologic therapy, endoscopic injection of botulinum toxin, pneumatic dilatation, or laparoscopic myotomy. Of these, pneumatic dilatation and myotomy are considered the most effective treatment, ${ }^{2}$ with a favorable short-term outcome. However, the beneficial effect declines over time, and repeat intervention may be required. $^{3}$

When compared with surgical myotomy, peroral endoscopic myotomy (POEM) is known to be a safe and effective form of endoscopic surgery for achalasia patients. Inoue and colleagues introduced POEM as an alternative treatment for achalasia patients in 2010. ${ }^{4,5}$ POEM has been performed worldwide in more than 7,000 cases, there is growing evidence that POEM can be a standard treatment for achalasia patients.

Recent studies have reported excellent outcomes for POEM in terms of both symptom resolution and improvement in esophagogastric junction (EGJ) physiology and esophageal emptying. The treatment success rate of $89 \%$ to $100 \% 0^{4,6-9}$ have been reported for the treatment.

Response to botulinum toxin injection or pneumatic dilatation was best in type II achalasia and somewhat lower in type I; patients with type III achalasia had a poor response to all forms of therapy, which is similar in laparoscopic Heller's myotomy. ${ }^{9-11}$

However, the treatment outcomes for POEM, divided according to achalasia subtype as defined by high resolution manometry (HRM) have rarely been studied to the best of our knowledge. We therefore evaluated whether manometric subtype was associated with the treatment outcome in patients treated with POEM.

Correspondence to: Joo Young Cho

Digestive Disease Center, CHA Bundang Medical Center, CHA University, 59 Yatap-ro, Bundang-gu, Seongnam 13496, Korea

Tel: +82-31-780-5641, Fax: +82-31-780-5219, E-mail: cjy6695@cha.ac.kr

Received on November 8, 2016. Revised on January 3, 2017. Accepted on January 3, 2017. Published online June 27, 2017

pISSN 1976-2283 eISSN 2005-1212 https://doi.org/10.5009/gnl16545

(ङ) This is an Open Access article distributed under the terms of the Creative Commons Attribution Non-Commercial License (http://creativecommons.org/licenses/by-nc/4.0) which permits unrestricted non-commercial use, distribution, and reproduction in any medium, provided the original work is properly cited. 


\section{MATERIALS AND METHODS}

\section{Patients}

This retrospective cohort study was conducted from November 2011 to December 2014 in two tertiary referral centers. This study was approved by the Institutional Review Board of Soonchunhyang University Hospital and CHA Bundang Medical Center, CHA University. Informed consent was obtained from all subjects. A total of 83 achalasia patients who underwent POEM were enrolled in our study. The diagnosis of achalasia was based on HRM. In addition, patients were required to have an Eckardt score of more than $3 .^{12}$ The Eckardt score is the sum of the symptom scores for dysphagia, regurgitation, and chest pain
(0, absent; 1, occasional; 2, daily; and 3, each meal) and weight loss (0, no weight loss; $1,<5 \mathrm{~kg} ; 2,5$ to $10 \mathrm{~kg}$; and 3, >10 kg). Patients were followed postoperatively, every 3 months periods.

\section{High resolution manometry}

The manometric data were collected pretreatment and at 12 months postoperatively. An HRM with 32 solid-state sensors spaced at $1 \mathrm{~cm}$ intervals (InSIGHT ${ }^{\mathrm{TM}} \mathrm{HRiM}^{*}$ system; Sandhill Scientific, Highlands Ranch, CO, USA) was used. Studies were performed with the patient in the sitting position after at least 6 hours of fasting. The manometric protocol included a 5-minute period to assess basal sphincter pressure and ten $5 \mathrm{~mL}$-saline swallows.

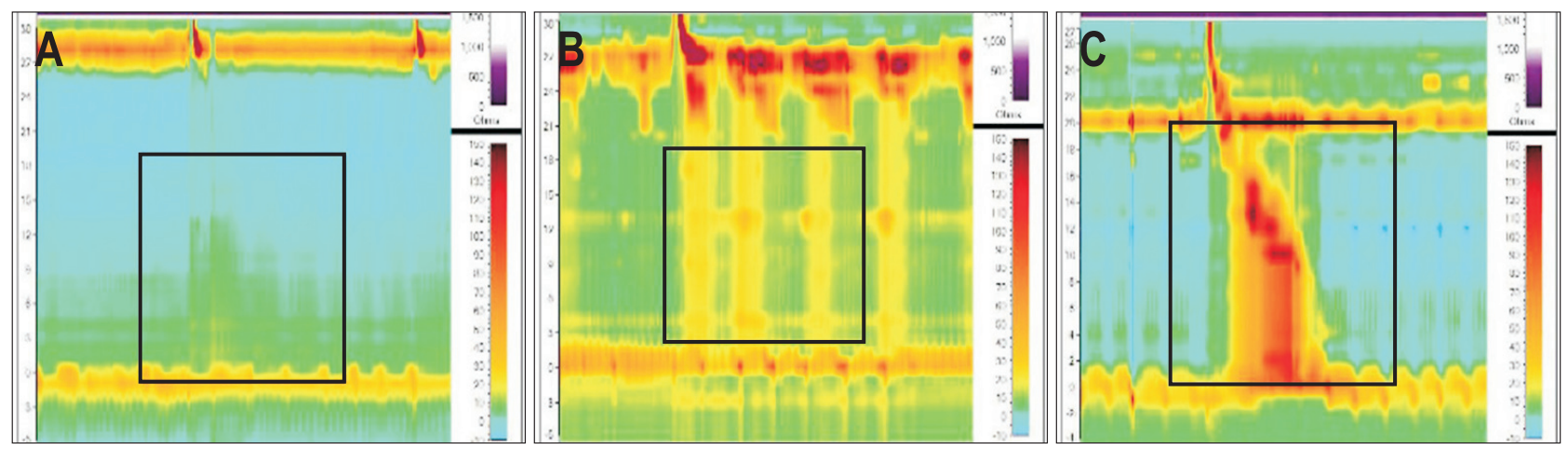

Fig. 1. High-resolution manometry tracings of the three subtypes of achalasia. (A) Type I achalasia, (B) type II achalasia, and (C) type III achalasia.
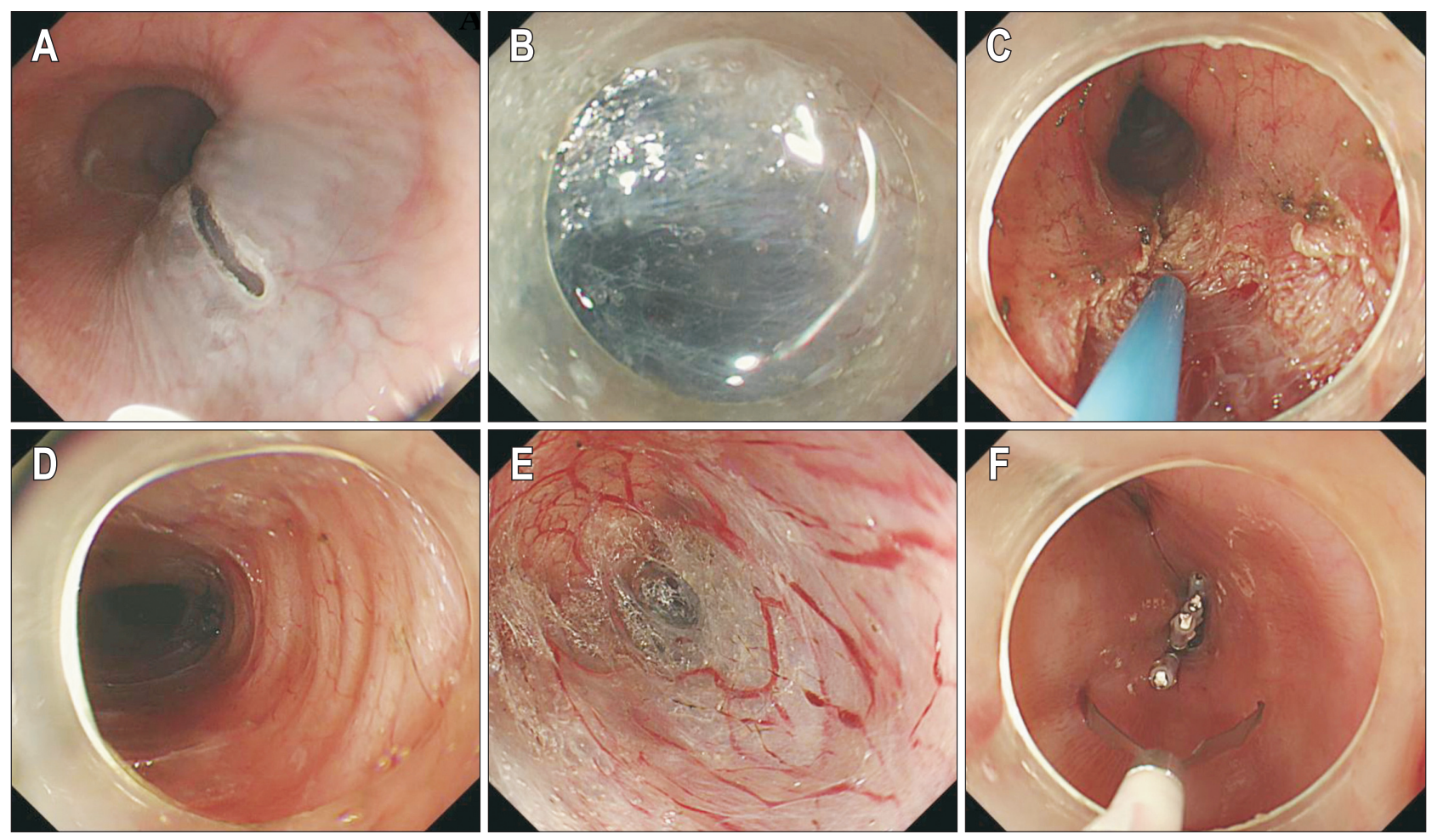

Fig. 2. Peroral endoscopic myotomy (POEM) procedure. (A) Mucosal incision, (B) creation of a submucosal tunnel, (C) myotomy, (D, E) submucosal space difference between the esophageal and gastric side, and (F) closure. 
Manometric data were analyzed using the BioView software (Sandhill Scientific Inc.). Manometric tracings were classified according to the three Chicago subtypes: $:^{13}$ type I with impaired LES relaxation during swallow and aperistalsis of esophageal body, type II with pan-esophageal pressurization, type III with no normal peristalsis, but evidence of esophageal spasm (Fig. 1). The manometries were interpreted by experienced gastroenterologists (T.H.L. and W.H.K.).

\section{POEM procedures}

POEM was performed under general anesthesia by expert endoscopists (J.Y.C. and S.J.H.). The procedure consisted of four consecutive steps: (1) mucosal incision: after $5 \mathrm{~mL}$ submucosal injection (mixture of sodium hyaluronate, normal saline, and indigo carmine), about $2 \mathrm{~cm}$ length vertical mucosal incision is made at 10 to $15 \mathrm{~cm}$ above the EGJ to allow entry into the submucosa; (2) creation of a submucosal tunnel: submucosal tunnel was made using spray coagulation until the LES was reached; (3) myotomy: dissection of the inner circular muscle bundle was started inside the submucosal tunnel, $2 \mathrm{~cm}$ distal to the mucosal entry site and more than $10 \mathrm{~cm}$ proximal to the EGJ. The myotomy should be extended $2 \mathrm{~cm}$ to the stomach cardia; and (4) closure: the mucosal entry was closed with multiple endoscopic clips (Fig. 2).

\section{Outcomes measurements}

Eckardt score was recorded every 3 months periods. HRM and Endoscopy was performed 6 months and 12 months after POEM. The primary outcome was therapeutic success, defined by a reduction in the Eckardt score to $\leq 3$. The secondary outcomes were LES pressure and integrated relaxation pressure (IRP) measured by HRM and other procedure related parameters.

\section{Statistical analysis}

Statistical analysis was performed using SPSS 21.0 software (IBM Corp., Armonk, NY, USA). The mean values between baseline and follow-up were compared using Wilcoxon signed rank test for paired samples. Statistical significance between groups was evaluated using analysis of variance. A p-values of less than 0.05 was considered statistically significant.

\section{RESULTS}

\section{Patient characteristics}

In total, 83 achalasia patients with a mean age of 45.2 years (range, 12 to 75 years) and 35 male patients (42.2\%) were enrolled in the study. The mean duration of symptoms was 6.4 years, and 40 patients had received prior treatment for achalasia. Of them, 18 patients had $30 \mathrm{~mm}$ balloon dilatation, 12 had botulinum toxin injection, two had both balloon dilatation and botulinum toxin injection, two had laparoscopic Heller myotomy, and six had POEM (Table 1).

In total, 48 patients had achalasia type I (57.8\%), 24 patients had achalasia type II (28.9\%), and 11 patients had achalasia type III (13.3\%). There was no difference in the pre-POEM Eckardt score, basal LES pressure, and IRP between type I, type II, and type III groups $(6.1 \pm 2.1 \mathrm{~mm} \mathrm{Hg}$ vs $6.8 \pm 2.2 \mathrm{~mm} \mathrm{Hg}$ vs $6.6 \pm 2.0$ $\mathrm{mm} \mathrm{Hg}, \mathrm{p}=0.557 ; 26.1 \pm 13.8 \mathrm{~mm} \mathrm{Hg}$ vs $32.3 \pm 19.0 \mathrm{~mm} \mathrm{Hg}$ vs $36.8 \pm 19.2 \mathrm{~mm} \mathrm{Hg}, \mathrm{p}=0.137 ; 21.5 \pm 11.7 \mathrm{~mm} \mathrm{Hg}$ vs $24.5 \pm 14.8$ $\mathrm{mm} \mathrm{Hg}$ vs $24.0 \pm 15.5 \mathrm{~mm} \mathrm{Hg}, \mathrm{p}=0.618$ ).

\section{Outcomes of POEM}

All of the POEMs were successfully performed without any serious complications. There was no significant difference in therapeutic success between the previously treated and treatment naive patients (97.4\% vs 100\%, $\mathrm{p}=0.433)$. Also, treatment success rate was similar in two independent endoscopists (67/69 [97.1\%] vs 14/14 [100\%], $\mathrm{p}=0.519$ ) (Supplement Table 1).

Capnoperitoneum occurred in $12.5 \%$ of patients, and was resolved with conservative treatment in all patients. Mucosal perforation was occurred in one patient. The mean procedure time of 83 patients was $91.1 \pm 35.8$ minutes, mean length of the submucosal tunnel created was $12.2 \pm 3.3 \mathrm{~cm}$, and the average length of myotomy was $9.0 \pm 2.8 \mathrm{~cm}$. The procedure time, myotomy length, nil per os time, and hospital stay were no significantly different between the groups (Table 2).

Treatment success, defined as an Eckardt score of $<3$, was achieved in all the three groups, 97.9\% in type I, 100\% in II patients, and 90.9\% in type III. The success rate was not different between groups $(p=0.179)$. All three groups of patients showed a significant improvement in post-POEM Eckardt score at the me-

Table 1. Previous Treatment Modalities

\begin{tabular}{|c|c|c|c|c|}
\hline & Type $1(\mathrm{n}=48)$ & Type $2(n=24)$ & Type $3(n=11)$ & p-value \\
\hline Previous treatment & & & & 0.902 \\
\hline Botulinum toxin injection & $7(16.7)$ & $4(14.8)$ & $1(7.1)$ & \\
\hline Pneumatic balloon dilatation & $10(23.8)$ & $4(14.8)$ & $4(28.6)$ & \\
\hline Both toxin and balloon & $2(4.8)$ & 0 & 0 & \\
\hline Laparoscopic Heller's myotomy & $1(2.4)$ & $1(3.7)$ & 0 & \\
\hline POEM & $3(7.1)$ & $2(7.4)$ & $1(7.1)$ & \\
\hline
\end{tabular}

Data are presented as number (\%). POEM, peroral endoscopic myotomy. 
Table 2. Comparison of Perioperative Details among Groups

\begin{tabular}{lcccc}
\hline \multicolumn{1}{c}{ Variable } & Type $1(\mathrm{n}=48)$ & Type $2(\mathrm{n}=24)$ & Type 3 $(\mathrm{n}=11)$ & $\mathrm{p}$-value \\
\hline Time of procedure, min & $103.7 \pm 44.2$ & $86.0 \pm 25.5$ & $82.5 \pm 33.3$ & 0.212 \\
NPO time, day & $5.1 \pm 2.3$ & $5.5 \pm 1.8$ & $4.6 \pm 2.0$ & 0.634 \\
Length of myotomy, cm & & & & 0.787 \\
$\quad$ Total & $9.0 \pm 3.0$ & $8.5 \pm 1.6$ & $9.3 \pm 2.8$ & 0.889 \\
Esophageal & $7.2 \pm 2.6$ & $6.6 \pm 1.6$ & $7.8 \pm 2.4$ & 0.417 \\
Gastric & $1.8 \pm 0.9$ & $2.0 \pm 0.4$ & $1.6 \pm 0.8$ & 0.293 \\
\hline
\end{tabular}

Data are presented as mean \pm SD.

NPO, nil per os.

Table 3. Treatment Outcomes after Peroral Endoscopic Myotomy

\begin{tabular}{|c|c|c|c|c|}
\hline Variable & Type $1(\mathrm{n}=48)$ & Type $2(\mathrm{n}=24)$ & Type $3(n=11)$ & p-value \\
\hline Treatment success (Eckardt score $\leq 3$ ) & $47(97.9)$ & $24(100)$ & $10(90.9)$ & 0.179 \\
\hline \multicolumn{5}{|l|}{ Eckardt score } \\
\hline Before POEM & $6.1 \pm 2.1$ & $6.8 \pm 2.2$ & $6.6 \pm 2.0$ & 0.557 \\
\hline After POEM & $1.5 \pm 1.5$ & $1.2 \pm 0.9$ & $1.6 \pm 1.4$ & 0.838 \\
\hline Before and after-POEM difference & $4.8 \pm 2.5$ & $5.4 \pm 2.8$ & $5.0 \pm 2.1$ & 0.793 \\
\hline \multicolumn{5}{|l|}{ LES pressure, $\mathrm{mm} \mathrm{Hg}$} \\
\hline Before POEM & $26.1 \pm 13.8$ & $32.3 \pm 19.0$ & $36.8 \pm 19.2$ & 0.137 \\
\hline After POEM & $15.4 \pm 6.8$ & $19.2 \pm 10.4$ & $17.5 \pm 9.7$ & 0.670 \\
\hline Before and after-POEM difference & $8.7 \pm 16.5$ & $17.1 \pm 17.9$ & $20.6 \pm 26.4$ & 0.366 \\
\hline \multicolumn{5}{|l|}{ IRP, mm Hg } \\
\hline Before POEM & $21.5 \pm 11.7$ & $24.5 \pm 14.8$ & $24.0 \pm 15.7$ & 0.618 \\
\hline After POEM & $12.0 \pm 8.7$ & $12.0 \pm 7.6$ & $11.8 \pm 7.1$ & 0.969 \\
\hline Before and after-POEM difference & $7.8 \pm 13.0$ & $14.7 \pm 16.1$ & $12.8 \pm 16.0$ & 0.553 \\
\hline
\end{tabular}

Data are presented as number (\%) or mean \pm SD.

POEM, peroral endoscopic myotomy; LES, lower esophageal sphincter; IRP, integrated relaxation pressure.

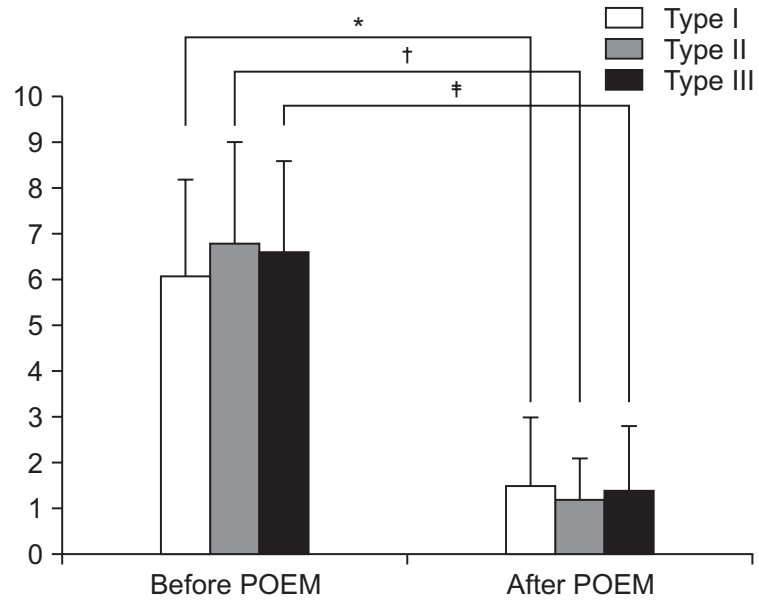

Fig. 3. Eckardt score before and after peroral endoscopic myotomy (POEM). ${ }^{*} \mathrm{p}=0.001 ;{ }^{\dagger} \mathrm{p}=0.001 ;{ }^{\dagger} \mathrm{p}=0.011$.

dian follow-up of 16 months (Fig. 3). There was no significant difference in mean post-POEM Eckardt score between groups, but decreased degree of Eckardt score was most high in type II achalasia patients (Table 3).

LES pressure $(26.1 \pm 13.8$ to $15.4 \pm 6.8, \mathrm{p}=0.018 ; 32.3 \pm 19.0$ to $19.2 \pm 10.4, p=0.003 ; 36.8 \pm 19.2$ to $17.5 \pm 9.7, p=0.041$ ), and $4 \mathrm{~s}$ IRP $(21.5 \pm 11.7$ to $12.0 \pm 8.7, \mathrm{p}=0.007 ; 24.5 \pm 14.8$ to $12.0 \pm 7.6$, $\mathrm{p}=0.002 ; 24.0 \pm 15.7$ to $11.8 \pm 7.1, \mathrm{p}=0.019$ ) decreased after POEM in all three groups of patients. IRP decreased the most in type II achalasia patients (Table 3).

A total of 18 patients had endoscopic reflux esophagitis: $16.7 \%(8 / 48)$ of patients with achalasia type I, 33.3\% (8/24) of type II, and 18.2\% (2/11) of type III. The incidence of reflux esophagitis was not different between the subtype groups $(\mathrm{p}=0.553)$.

\section{DISCUSSION}

POEM is suggested as an effective treatment option for achalasia, however, it remains controversial due to a paucity of data from randomized controlled trial, ${ }^{5}$ and the use of relatively short follow-up periods. There is also a shortage of studies on the predictors of therapeutic success and prognosis of POEM. 
Since the introduction of HRM, achalasia has been divided into three subtypes. The treatment outcome was different on achalasia subtypes and suggests that the subtyping of achalasia allows the clinician to direct therapy and improve predicted outcomes. ${ }^{9-11,14}$

In studies of pneumatic dilatation, achalasia subtype classified by HRM was found to be an important predictor of the treatment success and prognosis. ${ }^{11}$ The type II achalasia subtype was most frequent in Western, ${ }^{11,14,15}$ Asian, ${ }^{16,17}$ and Korean ${ }^{6,18,19}$ studies and was found to be more responsive to treatment (95.3\% to $100 \%$ ). The same is true in the case of laparoscopic Heller's myotomy (LHM). ${ }^{9,10,14}$ Most studies reported that the type III patients had the lowest response rate to pneumatic dilatation and LHM, and reported treatment success rate was $29 \%$ to $86 \% .^{2,9,10,14}$

In our study, treatment success was achieved in all three subtypes, and all parameters improved after POEM. In the patients with type II achalasia, treatment success was achieved 100\%, and the difference between the pre- and post-POEM Eckardt score and IRP was highest of the three groups.

Even as type III, 10 out of 11 of those belonging to the type III group (90.9\%) achieved treatment success; postoperative Eckardt score $\leq 3$ and improved chest pain. Although the number of patients was not many, the treatment success rate of POEM was much higher than pneumatic dilatation or LHM. ${ }^{20,21}$ Type III achalasia has spastic contractions in the mid and distal esophagus. Therefore, reducing the pressure of LES as well as the segment affected spastic motility is also required. Unlike LHM, POEM allows access to the entire length of the esophageal body, therefore long myotomy can be performed. ${ }^{21}$ The higher success rate of POEM in type III achalasia may be due to long myotomy of esophageal body. There are few data about the role of POEM in the management of patients with type III achalasia, and this study can be an additional evidence for POEM as effective treatment modality for type III achalasia.

Unlike other studies, the type I subtype was most common in our study (57.8\%). Till date, POEM was not been widely accepted in Korea. Therefore, POEM was frequently performed as a second line therapy after the failure of the first line therapy such as medication, pneumatic balloon dilatation, and Botox injection. In our study, 40 out of 83 patients (48.2\%) had received prior treatment. It is possible that achalasia type II responded relatively well to other treatments; therefore, many of these patients were excluded from our study. There may have been a bias towards recruiting patients with type I achalasia, as suggested by the history of previous treatment, which was highest in the type I achalasia group.

Only one patient (1.6\%) had recurrence after 12 months, and that was only of a mild degree. A total of 18 patients (21.7\%) had endoscopic reflux esophagitis. Reflux symptoms were easily controlled with proton pump inhibitor. There was no difference in the recurrence or reflux symptoms between the groups. In the surgical literature, the basal LES pressures are expected to approach $10 \mathrm{~mm} \mathrm{Hg}$ after myotomy. In out study, basal LES pressure after POEM are from 15.4 to $19.2 \mathrm{~mm} \mathrm{Hg}$. Relatively shorter lengths of myotomy on the gastric side may account for this, and the low rate of reflux.

Our study has several limitations. This includes the small sample size, with only 11 type III patients enrolled. Data on the postprocedure incidence of reflux esophagitis, or medication for $\mathrm{RE}$, were not always available. Our study also included only one patient with sigmoid type achalasia.

Nevertheless, this study is useful as the first study to determine the therapeutic outcome of POEM by manometric subtypes, and the predictors of treatment outcome and the precise indications of POEM.

Of special note is that the type III achalasia subtype, that showed poor response to any other treatment modality, had a high success rate of 90.9\% with POEM. Therefore, POEM should be a particularly useful treatment modality in type III achalasia patients.

In conclusion, POEM is an endoscopic procedure of relatively low invasiveness and shows good clinical outcomes for esophageal achalasia without serious complications. POEM appears to be a very effective treatment for achalasia patients, regardless of the manometric subtype. POEM may be of the most effectiveness in type II patients like other studies, and it is particularly useful treatment modality in type III achalasia subtype.

One concern is that, there was some difference in the success rate according to the practitioner, experienced professionals or trainees under the guidance of professionals are needed to perform POEM. A large prospective study with long-term follow-up is needed to confirm that POEM can be considered as a standard treatment in any subtype of achalasia patients.

\section{CONFLICTS OF INTEREST}

No potential conflict of interest relevant to this article was reported.

\section{ACKNOWLEDGEMENTS}

The abstract of this manuscript has been a poster presentation at United European Gastroenterology Week 2015. Neither the submitted manuscript nor portions thereof have been published previously or are under consideration for publication elsewhere.

\section{REFERENCES}

1. Vela MF. Management strategies for achalasia. Neurogastroenterol Motil 2014;26:1215-1221.

2. Boeckxstaens GE, Annese V, des Varannes SB, et al. Pneumatic dilation versus laparoscopic Heller's myotomy for idiopathic achalasia. N Engl J Med 2011;364:1807-1816. 
3. Vela MF, Richter JE, Khandwala F, et al. The long-term efficacy of pneumatic dilatation and Heller myotomy for the treatment of achalasia. Clin Gastroenterol Hepatol 2006;4:580-587.

4. Inoue H, Minami H, Kobayashi Y, et al. Peroral endoscopic myotomy (POEM) for esophageal achalasia. Endoscopy 2010;42:265271.

5. Bredenoord AJ, Rösch T, Fockens P. Peroral endoscopic myotomy for achalasia. Neurogastroenterol Motil 2014;26:3-12.

6. Bhayani NH, Kurian AA, Dunst CM, Sharata AM, Rieder E, Swanstrom LL. A comparative study on comprehensive, objective outcomes of laparoscopic Heller myotomy with per-oral endoscopic myotomy (POEM) for achalasia. Ann Surg 2014;259:10981103.

7. Hungness ES, Teitelbaum EN, Santos BF, et al. Comparison of perioperative outcomes between peroral esophageal myotomy (POEM) and laparoscopic Heller myotomy. J Gastrointest Surg 2013;17:228235.

8. von Renteln D, Inoue H, Minami H, et al. Peroral endoscopic myotomy for the treatment of achalasia: a prospective single center study. Am J Gastroenterol 2012;107:411-417.

9. Pandolfino JE, Kwiatek MA, Nealis T, Bulsiewicz W, Post J, Kahrilas PJ. Achalasia: a new clinically relevant classification by highresolution manometry. Gastroenterology 2008;135:1526-1533.

10. Salvador R, Costantini M, Zaninotto G, et al. The preoperative manometric pattern predicts the outcome of surgical treatment for esophageal achalasia. J Gastrointest Surg 2010;14:1635-1645.

11. Pratap N, Kalapala R, Darisetty S, et al. Achalasia cardia subtyping by high-resolution manometry predicts the therapeutic outcome of pneumatic balloon dilatation. J Neurogastroenterol Motil 2011;17:48-53.

12. Eckardt VF. Clinical presentations and complications of achalasia.
Gastrointest Endosc Clin N Am 2001;11:281-292.

13. Kahrilas PJ, Bredenoord AJ, Fox M, et al. The Chicago classification of esophageal motility disorders, v3.0. Neurogastroenterol Motil 2015;27:160-174.

14. Rohof WO, Salvador R, Annese V, et al. Outcomes of treatment for achalasia depend on manometric subtype. Gastroenterology 2013;144:718-725.

15. Roman S, Zerbib F, Quenehervé L, Clermidy H, Varannes SB, Mion F. The Chicago classification for achalasia in a French multicentric cohort. Dig Liver Dis 2012;44:976-980.

16. Min M, Peng LH, Yang YS, et al. Characteristics of achalasia subtypes in untreated Chinese patients: a high-resolution manometry study. J Dig Dis 2012;13:504-509.

17. Yamashita H, Ashida K, Fukuchi T, et al. Predictive factors associated with the success of pneumatic dilatation in Japanese patients with primary achalasia: a study using high-resolution manometry. Digestion 2013;87:23-28.

18. Lee JY, Kim N, Kim SE, et al. Clinical characteristics and treatment outcomes of 3 subtypes of achalasia according to the Chicago classification in a tertiary institute in Korea. J Neurogastroenterol Motil 2013;19:485-494.

19. Lee BH, Shim KY, Hong SJ, et al. Peroral endoscopic myotomy for treatment of achalasia: initial results of a Korean study. Clin Endosc 2013;46:161-167.

20. Ju H, Ma Y, Liang K, Zhang C, Tian Z. Function of high-resolution manometry in the analysis of peroral endoscopic myotomy for achalasia. Surg Endosc 2016;30:1094-1099.

21. Kumbhari V, Tieu AH, Onimaru M, et al. Peroral endoscopic myotomy (POEM) vs laparoscopic Heller myotomy (LHM) for the treatment of type III achalasia in 75 patients: a multicenter comparative study. Endosc Int Open 2015;3:E195-E201. 